Volume 1 Nomor 1, Maret 2019, Halaman 17 - 30

\title{
PENYULUHAN KEBERSIHAN LINGKUNGAN SEKOLAH UNTUK MENINGKATKAN PENGETAHUAN PADA SISWA SDN TERUSAN 1 INDRAMAYU
}

\author{
Sarinah Basri K \\ Universitas Wiralodra, b_sarinah@yahoo.com
}

\begin{abstract}
Abstrak
Penyuluhan Kesehatan mempunyai tujuan mengubah atau mempengaruhi perilaku manusia secara individu, kelompok maupun masyarakat untuk dapat lebih mandiri dalam mencapai tujuan hidup sehat. Dalam penyuluhan kesehatan ini diperlukan metode agar penyampaian pesan dapat sesuai yang diharapkan. Penyampaian metode dalam penyuluhan ini adalah dengan menggunakan ceramah, video, serta aksi terhadap kebersihan lingkungan. Dengan Kegiatan ini siswa diharapkan mampu meningkatkan pengetahuan kebersihan lingkungan sekolahnya seperti membuang sampah pada tempatnya, dapat membedakan sampah organik dan anorganik, tidak mencoret-coret dinding dan meja dan secara sadar mau bergotong royong untuk membersihkan halaman dan ruangan kelas. Pelaksanaan pengabdian perlu adanya kerjasama berbagai pihak agar penyuluhan kesehatan dapat dilakukan tidak hanya sekali, namun dilakukan rutin guna memantau perkembangan pengetahuan siswa mengenai kebersihan lingkungan di Sekolah. Selain ceramah, video dan aksi, penerapan atau penyampaian pendidikan kesehatan juga dapat menggunakan media permainan edukatif karena dengan media permainan siswa dapat lebih mudah memahami, siswa juga tidak mengalami kebosanan dalam penyampaian materi.
\end{abstract}

\section{Kata Kunci : Ceramah, Video, Aksi}

\begin{abstract}
Abstrak
Health education has the purpose of changing or influencing human behavior individually, in groups and communities to be more independent in achieving the goals of healthy living. In this health education method is needed so that the delivery of messages can be as expected. Submission of methods in counseling is to use lectures, videos, and actions on environmental cleanliness. With this activity students are expected to be able to increase knowledge of the cleanliness of the school environment such as disposing of garbage in its place, being able to distinguish organic and inorganic waste, not scribbling walls and tables and consciously wanting to work together to clean the yard and classrooms. The implementation of service requires the collaboration of various parties so that health education can be done not only once, but it is conducted routinely to monitor the development of students' knowledge regarding environmental hygiene
\end{abstract}


in schools. In addition to lectures, videos and actions, the application or delivery of health education can also use educational media games because with game media students can more easily understand, students also do not experience boredom in delivering material.

\section{Keywords: Lecture, Video, Action}

\section{PENDAHULUAN}

Kesehatan merupakan salah satu unsur yang sangat penting dari mutu kehidupan dalam pembangunan nasional untuk mewujudkan manusia Indonesia seutuhnya. Berdasarkan UU No. 36 tahun 2009 pasal 3 bahwa pembangunan kesehatan bertujuan untuk meningkatkan kesadaran, kemauan, dan kemampuan hidup sehat bagi setiap orang agar terwujud derajat kesehatan masyarakat yang setinggitingginya, sebagai investasi bagi pembangunan sumber daya manusia yang produktif secara sosial dan ekonomis. Keberhasilan pembangunan kesehatan membutuhkan sumber daya manusia yang berkualitas. Kualitas hidup manusia dipengaruhi oleh tingkat kesehatan manusia sejak usia dini. Salah satu masa yang penting dan perlu mendapat perhatian adalah masa usia sekolah (6-15 tahun).

Pada usia sekolah, siswa sering mendapatkan masalah kesehatan akibat faktor lingkungan. Kondisi lingkungan sekolah akan sangat berpengaruh terhadap perkembangan fisik anak. Siswa yang sehat secara fisik tentunya akan lebih mampu untuk berpartisipasi aktif dalam proses pembelajaran sehingga berimplikasi positif pada prestasi akademiknya. (Adrianus, 2014). Eagle Awards Documentary Competition (2016) juga menyebutkan bahwa faktor penting untuk mencapai Indonesia sehat menyangkut pada kesehatan masyarakat, kesehatan lingkungan, pelayanan kesehatan, inovasi dan pengembangan, partisipasi publik. Permasalah lingkungan tersebut dapat menyebabkan penyakit menular. (Arief, 2013).

Penyakit menular yang banyak diderita anak usia sekolah antara lain adalah diare, tifus, ISPA, malaria dan infeksi parasit usus. Penyakit Malaria, ISPA dan diare menjadi risiko penyakit penyebab kematian pada anak usia sekolah. Status kesehatan merupakan faktor penting dalam pencapaian "pendidikan untuk semua" (Education for All) dan tujuan Millennium Development Goals (MDGs). (Rosso, 
ddk. 2009). Kemudian dalam perubahan MDGs ke Sustainable Development Goals (SDGs) juga sangat memperhatikan kesehatan anak sekolah dalam hal ini penyakit yang diderita anak usia sekolah sehingga dapat mempengaruhi kehadirannya di sekolah oleh karena itu prioritas SDGs yang telah dituangkan secara tersurat di dalam RPJMN 2016-2020 memberi dukungan terhadap peningkatan angka kehadiran sekolah dasar.

Menurut Riskesdas (2013), periode prevalensi ISPA (25,0\%), malaria $(6,0 \%)$, kecacingan saat ini berkisar $20-86 \%$ dengan rata-rata $30 \%$ dan pada tahun 2015 diperkirakan terdapat 100.000 lebih anak dibawah 5 tahun meninggal karena Diare. (Dirjen Pengendalian Penyakit dan Penyehatan Lingkungan, 2015)

Berbagai upaya dilakukan untuk mencegah penyebaran penyakit menular disekolah yang diakibatkan oleh lingkungan. Salah satunya adalah menerapkan perilaku hidup bersih dan sehat melalui upaya penyehatan lingkungan di tingkat institusi pendidikan. Perilakunya seperti mencuci tangan dengan air yang mengalir dan menggunakan sabun, mengkonsumsi jajan di kantin sekolah, menggunakan jamban yang bersih dan sehat, buang sampah di tempatnya, memberantas jentik nyamuk, dan tidak merokok di sekolah. Penerapan perilaku kebersihan lingkungan pada anak sekolah lebih cenderung menirukan apa yang pernah mereka lihat dan mereka peroleh dari pengetahuan yang diberikan oleh orang tua maupun guru di sekolah. Peranan siswa dalam arti kata kemampuan kognitif dan afektif dan keikutsertaannya dalam permasalahan lingkungan perlu dibina dan dikembangkan, sebab siswa mempunyai peranan penting sekali dalam menciptakan lingkungan yang sehat. Kognitif menekankan pada pengetahuan (Knowledge) siswa mengenai kebersihan lingkungan. Pemahaman siswa merupakan awal pertama untuk menciptakan lingkungan yang bersih, karena dengan adanya ilmu pengetahuan siswa maka akan timbul rasa, kesadaran, kepedulian, bahkan rasa akan mau menciptakan lingkungan yang bersih dan nyaman.

Berdasarkan beberapa survei yang dilakukan di beberapa sekolah dasar yang ada di Indramayu mempunyai kondisi lingkungan yang kurang terawat. Kondisi lingkungan yang kurang terawat dapat dilihat dari sampah yang 
berserakan terutama pada saat jam istirahat siswa cenderung membuang sampah di pekarangan sekolah maupun di dalam kelas, hal ini bukan saja karena perilaku siswa tentang sanitasi yang buruk namun juga karena kurangnya tersedia tempat sampah. Begitupula dengan toilet tidak dalam keadaan bersih, siswa yang telah menggunakan toilet tidak membersihkan toilet tersebut sehingga meninggalkan bau yang tidak sedap, terdapat jentik nyamuk didalam bak air dan banyak ditemui genangan air yang dapat menjadi tempat perindukan bagi nyamuk dan juga kurangnya tersedia air bersih.

Penjelasan diatas menunjukkan bahwa kondisi lingkungan, pengetahuan siswa tentang kebersihan lingkungan di sekolah dan partisipasinya untuk membersihkan lingkungan tersebut masih kurang sehingga penerapan pendidikan kesehatan tentang kebersihan lingkungan perlu diadakan di sekolah tersebut. Pendidikan kesehatan dapat dilakukan melalui penyuluhan kesehatan.

Penyuluhan kesehatan adalah penambahan pengetahuan dan kemampuan seseorang melalui tehnik praktek belajar atau instruksi dengan tujuan mengubah atau mempengaruhi perilaku manusia secara individu, kelompok maupun masyarakat untuk dapat lebih mandiri dalam mencapai tujuan hidup sehat (Depkes, 2002).

Penyuluhan kesehatan adalah gabungan berbagai kegiatan dan kesempatan yang berlandaskan prinsip-prinsip belajar untuk mencapai suatu keadaan, dimana individu, keluarga, kelompok atau masyarakat secara keseluruhan ingin hidup sehat, tahu bagaimana caranya dan melakukan apa yang bisa dilakukan, secara perseorangan maupun secara kelompok dengan meminta pertolongan (Effendy, 2003).

Penyuluhan kesehatan yang dilakukan dalam pengabdian ini tidak hanya dalam bentuk ceramah namun dilakukan juga pemutaran video. Menurut Azizatul Yaumul Adha, Diah Rahayu Wulandari dan Ari Budi Himawan (2016), video merupakan alat bantu atau media penyuluhan yang berfungsi memberikan pesanpesan dengan menggunakan efek tertentu sehingga dapat memperkokoh proses pembelajaran dan dapat menarik perhatian penonton. 
Berdasarkan uraian diatas maka penyuluhan ini berjudul Penyuluhan Kebersihan Lingkungan Sekolah Untuk Meningkatkan Pengetahuan Pada Siswa SDN Terusan 1 Indramayu.

\section{METODE}

Pengabdian Masyarakat ini dilaksanakan di Siswa Kelas V SDN Terusan 1 Indramayu Kelurahan Terusan Kecamatan Indramayu. Metode yang digunakan dalam pengabdian kepada masyarakat ini adalah metode penyuluhan (Dengan ceramah dan pemutaran video), diskusi (tanya jawab), Aksi dan evaluasi dengan mengejarkan soal.

Dalam rancangan tersebut maka akan diberikan kuisioner yaitu pada pretest dan post-test. Pertama responden akan menerima pretest, kemudian akan menerima intervensi berupa penyuluhan. Setelah responden menerima intervensi maka akan menerima post-test. Selang waktu antara responden menerima pretest, intervensi dan posttest antara 15-30 hari. Adapun tahap penelitian yang dilaksanakan sebagai berikut:

1. Persiapan

Membuat proposal pengabdian, membuat surat ijin, mempersiapkan daftar siswa, dokumentasi, menyiapkan jadwal kegiatan dan membuat kuisioner pengabdian.

2. Pra pengabdian

Sebelum diadakan pengabdian, maka melakukan koordinasi dengan pihak sekolah baik kepada kepala sekolah, guru maupun siswa

3. Pelaksanaan Pengabdian di Sekolah

Adapun tahapan pengabdian di dalam kelas: a) Sebelum siswa menerima penyuluhan tentang kebersihan lingkungan dengan media ceramah, terlebih dahulu diadakan pretest, siswa akan menerima pretest berupa kuisioner dengan tujuan untuk mengukur kemampuan kognitif dan afektif peserta didik; b) intervensi setelah 2 minggu pelaksanaan pretest, peserta didik akan menerima intervensi berupa pemberian materi dan diskusi. 
Intervensi ini dilaksanakan selama 60 menit. c) posttest, dilakukan setelah 2 minggu pelaksanaan intervensi yang dilaksanakan selama 30 menit.

Selama kegiatan, materi penyuluhan disajikan dengan alokasi waktu $40 \%$, sedangkan $60 \%$ untuk diskusi dan tanya jawab sehingga para peserta lebih aktif dan kegiatan secara keseluruhan menjadi lebih hidup, adapun tahap pelaksanaan dan materi penyuluhan dapat dilihat dalam tabel 1 dan 2 berikut ini:

Tabel 1. Tahap Pelaksanaan Penyuluhan di SDN Terusan Indramayu

\begin{tabular}{|c|c|c|c|}
\hline No & Tahap/waktu & $\begin{array}{l}\text { Kegiatan } \\
\text { Penyuluhan }\end{array}$ & Kegiatan \\
\hline 1. & $\begin{array}{l}\text { Pembukaan: } \\
\text { (Pretest) } \\
1 \text { Minggu }\end{array}$ & $\begin{array}{ll}\text { a } & \begin{array}{l}\text { Memberi salam } \\
\text { pembuka }\end{array} \\
\text { b } & \begin{array}{l}\text { Memperkenalkan } \\
\text { diri }\end{array} \\
\text { c } & \text { Membagi } \\
& \text { kuisoner. } \\
\text { d } & \text { Menjelaskan } \\
& \text { pokok bahasan } \\
& \text { dan } \\
\text { tujuan penyuluh } \\
\text { an }\end{array}$ & $\begin{array}{ll}\text { a } & \text { Menjawab salam } \\
\text { b } & \text { Memperhatikan } \\
\text { c } & \text { Menjawab } \\
& \text { kuisoner }\end{array}$ \\
\hline 2. & $\begin{array}{l}\text { Pelaksanaan } \\
\text { Penyuluhan } \\
\text { (Intervensi) } \\
2 \text { Minggu }\end{array}$ & $\begin{array}{ll}\text { a. } & \text { Memberikan } \\
\text { materi } \\
\text { b. } \\
\text { Menanyakan } \\
\text { kepada siswa } \\
\text { tentang materi } \\
\text { yang telah } \\
\text { diberikan. } \\
\text { a Mempersilahkan } \\
\text { peserta bertanya }\end{array}$ & $\begin{array}{ll}\mathrm{a} & \text { Memperhatihan } \\
\mathrm{b} & \text { Mendengarkan } \\
\mathrm{c} & \text { Berkonsentrasi } \\
\mathrm{d} & \text { Tidak } \\
& \text { meninggalkan } \\
& \text { tempat } \\
& \text { penyuluhan } \\
& \text { Peserta } \\
& \text { bertanya } \\
\mathrm{e} & \text { Mendengarkan } \\
\mathrm{f} & \text { Menjawab } \\
& \text { pertanyaan } \\
\end{array}$ \\
\hline 3 & $\begin{array}{l}\text { Evaluasi dan } \\
\text { Penutupan } \\
\text { (Posttest) } \\
1 \text { Minggu }\end{array}$ & $\begin{array}{ll}\text { a. } & \text { Menyimpulkan } \\
\text { hasil penyuluhan } \\
\text { b. Membagikan } \\
\text { Kuisioner } \\
\text { Posttest } \\
\text { c. Memberi salam } \\
\text { penutup }\end{array}$ & $\begin{array}{l}\text { a. Mengerjakan soal } \\
\text { b. Menjawab salam }\end{array}$ \\
\hline
\end{tabular}


Tabel 2. Tahap Pelaksanaan Penyuluhan di SDN 1 Terusan Indramayu

\begin{tabular}{|c|c|c|c|}
\hline No & Materi & Metode & Bobot \\
\hline 1 & $\begin{array}{l}\text { Hubungan Manusia } \\
\text { dan Lingkungan }\end{array}$ & $\begin{array}{ll}\text { a } & \text { Ceramah } \\
\text { b } & \text { Diskusi }\end{array}$ & $\begin{array}{l}40 \% \\
60 \%\end{array}$ \\
\hline 2 & $\begin{array}{l}\text { Pemutaran film } \\
\text { tentang penyebab } \\
\text { pencemaran } \\
\text { lingkungan sekolah }\end{array}$ & $\begin{array}{ll}\text { a } & \text { Video dan Leaflet } \\
\text { b } & \text { Diskusi }\end{array}$ & $\begin{array}{l}40 \% \\
60 \%\end{array}$ \\
\hline 3 & $\begin{array}{l}\text { Penyakit akibat } \\
\text { lingkungan yang } \\
\text { buruk di sekolah }\end{array}$ & $\begin{array}{ll}\text { a } & \text { Video dan Leaflet } \\
\text { b } & \text { Diskusi }\end{array}$ & $\begin{array}{l}40 \% \\
60 \%\end{array}$ \\
\hline 4 & $\begin{array}{lr}\text { Cara } & \text { Mengatasi } \\
\text { dampak } & \text { buruk } \\
\text { lingkungan } & \text { dengan } \\
\text { aksi } & \text { peduli } \\
\text { kebersihan } & \\
\text { lingkungan } & \end{array}$ & $\begin{array}{ll}\text { a } & \text { Ceramah } \\
\text { b } & \text { Diskusi }\end{array}$ & $\begin{array}{l}40 \% \\
60 \%\end{array}$ \\
\hline
\end{tabular}

4. Pasca Pengabdian

Setelah dilakukan pengabdian, siswa masih diperbolehkan melengkapi data-data lain yang mungkin dibutuhkan.

\section{PEMBAHASAN}

Kegiatan Penyuluhan kesehatan adalah kegiatan pendidikan yang dilakukan dengan cara menyebarkan pesan, menanamkan keyakinan, sehingga masyarakat tidak saja sadar, tahu dan mengerti, tetapi juga mau dan bisa melakukan suatu anjuran yang ada hubungannya dengan kesehatan. Penyuluhan kesehatan adalah gabungan berbagai kegiatan dan kesempatan yang berlandaskan prinsip-prinsip belajar untuk mencapai suatu keadaan, dimana individu, keluarga, kelompok atau masyarakat secara keseluruhan ingin hidup 
sehat, tahu bagaimana caranya dan melakukan apa yang bisa dilakukan, secara perseorangan maupun secara kelompok dan meminta pertolongan (Depkes RI, 2009). Penyuluhan kesehatan yang dilakukan dalam pengabdian masyarakat ini adalah penyuluhan kesehatan untuk meningkatkan pengetahuan siswa terhadap kebersihan lingkungan. Realisasi Kegiatan ini berlangsung sebagai berikut:

\section{Pembukaan:}

Pembukaan pada pukul 09.00 WIB, dimulai dari memberikan salam pembukaan, dilanjutkan dengan doa, sambutan dan memperkenalkan diri. Tempat kegiatan ini berlangsung di ruangan kelas yang dihadiri oleh guru dan siswa SDN Terusan 1 Indramayu. Dalam acara pembukaan penyuluh menyampaikan maksud dan tujuan diadakan kegiatan ini, Penyuluh memberikan motivasi kepada seluruh siswa yang hadir agar dapat peduli terhadap lingkungan. Setelah acara pembukaan, penyuluh menyampaikan bahwa sebelum diberikan materi penyuluhan, siswa harus melakukan pretest dengan mengisi kuisioner dimaksud untuk mengetahui pengetahuan siswa sebelum mendapatkan pendidikan mengenai kebersihan lingkungan. Tingkat pengetahuan siswa SD kelas V tentang kebersihan lingkungan sekolah di SDN Terusan 1 Indramayu diukur dengan tes pilihan ganda yang berjumlah 20 butir soal dengan skor 1 jika jawaban benar dan 0 jika jawaban salah. Setelah data di tabulasi, dihitung dan dianalisis. Adapun Hasil Pretest Penyuluhan Kebersihan Lingkungan Sekolah Untuk Meningkatkan Pengetahuan Pada Siswa SDN Terusan 1 Indramayu disajikan dalam Grafik 1 berikut ini:

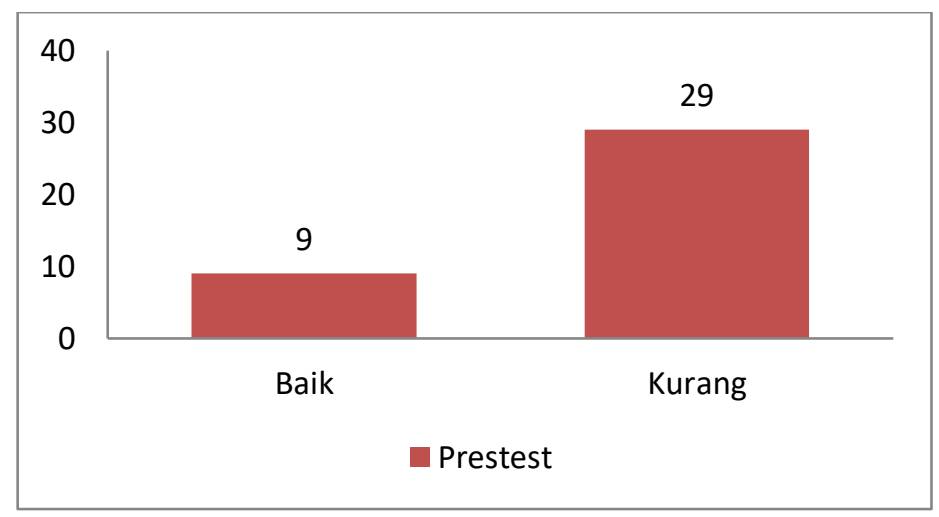

Grafik 1. Hasil Pretest Penyuluhan Kebersihan Lingkungan Sekolah 
Berdasarkan grafik, tingkat pengetahuan siswa sekolah dasar kelas V tentang kebersihan lingkungan sekolah di SDN 1 terusan yaitu sebanyak 9 siswa $(23,7 \%)$ yang memiliki pengetahuan baik dan sebanyak 29 siswa $(76,3 \%)$ yang memiliki pengetahuan kurang pada saat sebelum diberi penyuluhan, hal ini disebabkan banyak siswa yang kurang memahami pentingnya menjaga kebersihan lingkungan, masih ada beberapa siswa belum dapat membedakan antara sampah organik dan anorganik karena di sekolah belum membiasakan perilaku membuang sampah sesuai jenisnya, di sekolah juga hanya menyediakan satu jenis tempat sampah saja. Siswa juga belum memahami bahwa metode pemusnahan sampah organik, misalnya siswa membeli jajanan dari kantin sekolah, siswa tidak mengetahui bahwa sisa dari makanan/minuman tersebut dapat diolah kembali menjadi kompos. Selain itu, dalam menggunakan toilet di sekolah, mereka tidak memperhatikan kebersihannya sehingga toilet tersebut dapat meninggalkan bau yang tidak sedap.

\section{Pelaksanaan}

Setelah selesai mengadakan prestest, penyuluh kemudian memberikan materi yang dilaksanakan selama dua minggu. Pada sesi ini, sebagai penyuluh secara bersama-sama memberikan edukasi kepada siswa-siswi kelas V SDN Terusan 1 Indramayu mengenai pentingnya menjaga kebersihan lingkungan karena jika tidak dijaga maka akan berdampak buruk terhadap diri sendiri dan lingkungan sekitar. Adapun materi yang disampaikan :

a. Pemberian materi hubungan manusia dengan lingkungan diberikan melalui ceramah kepada siswa dengan bantuan media pembelajaran power point, dalam materi ini menjelaskan bahwa manusia erat kaitannya dengan lingkungan. Manusia dalam hidupnya senantiasa berinteraksi dengan lingkungan di mana manusia itu berada. Dengan adanya pemberian materi ini, siswa dapat mengetahui bahwa manusia itu tidak bisa hidup sendiri dan hidupnya saling ketergantungan. Siswa juga mengetahui di dalam sekolah harus terdapat lingkungan yang sehat, dimana indikatornya meliputi: a). tersedia jamban, b). ada air bersih, c). ada tempat sampah., d). ada 
SPAL (Saluran Pembuangan Air Limbah) e). ventilasi, f). ada warung sehat g). ada UKS, h). ada taman sekolah.

b. Dalam materi kedua dan ketiga, penyuluh memberikan materi dalam bentuk video dan membagikan leafleat kepada seluruh siswa kelas V SDN Terusan 1 Indramayu. Media video memiliki fungsi sebagai media pembelajaran yaitu fungsi atensi, fungsi afektif, fungsi kognitif dan fungsi kompensatoris (Arsyad 2002). Pemutaran video yang diberikan adalah mengenai penyebab dari pencemaran lingkungan disekolah dan akibat yang ditimbulkan jika tidak dijaga dengan baik. Pencemaran lingkungan disekolah seperti membuang sampah di sembarang tempat dengan membiarkan sampah plastik ataupun sisa jajanan berserakan dihalaman maupun ruangan kelas, membiarkan got/selokan tersumbat, tidak melepas sepatu/sandal saat berada diruangan, tidak merapikan ruangan kelas, lupa/tidak menyiram WC secara bersih setelah BAK/BAB, tidak membersihkan meja, tidak mengerjakan piket harian yang telah dibagikan oleh wali kelas, yakni mengepel dan menyapu lantai kelas, membakar sampah sehingga menimbulkan pencemaran udara dan mencoret dinding kelas maupun meja. Dari pemutaran video pertama tersebut mengenai pencemaran tersebut, siswa mendapatkan penjelasan bahwa akibat pencemaran di lingkungan sekolah dapat menimbulkan berbagai penyakit. Menurut Republika (2007) dalam Yoni Hermawan dan Komara Nur Ikhsan (2013) menyatakan anak sekolah menjadi salah satu kelompok paling rentan terhadap terjadinya masalah kesehatan karena faktor lingkungan dan pola hidup yang kurang baik. Data nasional menyebutkan $16 \%$ kejadian angka keracunan nasional terjadi di lingkungan sekolah, diare menempati urutan pertama dari angka kejadian infeksi saluran pencernaan pada tahun 2006-2010. Sedangkan 5.000 anak meninggal dunia setiap hari akibat serangan diare, prevalensi anemia $11,1-50,9 \%$ di tiap sekolah.

c. Dalam pelaksanaan terakhir ini, siswa diajarkan mengatasi dampak buruk lingkungan dengan aksi peduli kebersihan lingkungan. Dalam Aksi ini 
penyuluh mengajak siswa untuk membedakan sampah organik dan anorganik yang dibuang ditempat sampah serta siswa diajak secara langsung begotong royong membersihkan lingkungan sekitar.

\section{Evaluasi}

Kegiatan pengabdian melalui penyuluhan kepada Siswa kelas V SDN Terusan 1 Indramayu secara umum sudah berjalan dengan baik berkat kerjasama antara sekolah dengan pemateri dan bantuan serta dukungan berbagai pihak. Namun dalam pelaksanaan kedepannya diharapkan kegiatan ini dapat terlaksana lebih baik lagi dan meningkatkan koordinasi dari berbagai pihak. Keberhasilan kegiatan pengabdian ini dibuktikan dengan nilai hasil post-test siswa kelas V SDN Terusan 1 Indramayu yang meningkat, dapat dilihat dalam grafik 2 berikut ini:

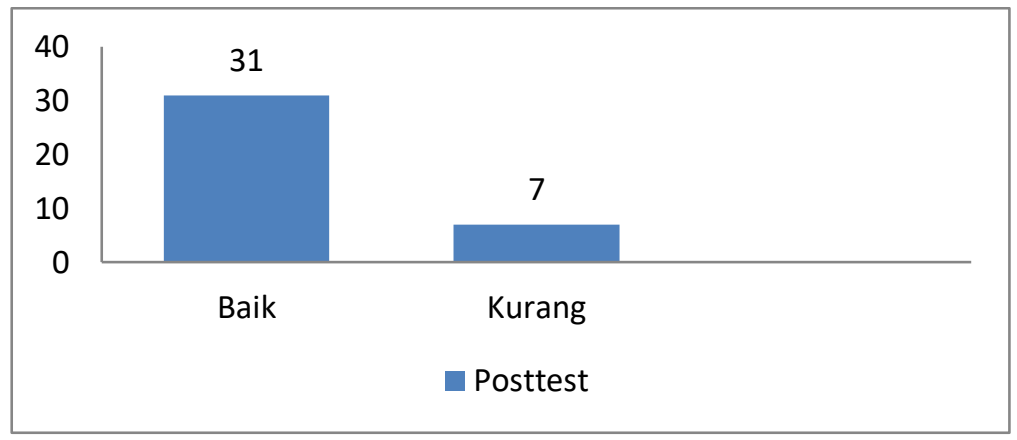

Grafik 2. Hasil Posttest Penyuluhan Kebersihan Lingkungan Sekolah

Dari grafik 1 sebelum diadakan penyuluhan, terlihat bahwa sebanyak 9 siswa $(23,7 \%)$ yang memiliki pengetahuan baik dan sebanyak 29 siswa $(76,3 \%)$ yang memiliki pengetahuan kurang namun setelah dilakukan intervensi dengan penyuluhan maka pengetahuan siswa pada saat posttest menjadi semakin meningkat, dapat dilihat dalam grafik 2 yakni sebanyak $31(81,6)$ siswa memiliki pengetahuan baik sedangkan hanya 7 siswa $(18,4 \%)$ yang memiliki pengetahuan kurang. ini berarti bahwa penyuluhan kesehatan lingkungan yang telah dilakukan sangat berpengaruh pada tingkat pengetahuan siswa akan pentingnya kebersihan lingkungan di sekolah. Dengan demikian memberikan indikasi jika diberikan 
penyuluhan kesehatan tentang kebersihan maka pengetahuan pada siswa salah menjadi meningkat, semakin intensif diberikan penyuluhan maka tingkat pengetahuan juga semakin baik, hal ini sejalan dengan penyuluhan yang dilakukan oleh Yoni Hermawan dan Komara NurIkhsan (2013) bahwa penyuluhan kesehatan sangat berpengaruh terhadap tingkat pengetahuan siswa tentang kesehatan lingkungan sekolah.

\section{SIMPULAN DAN ARAN}

1. Kegiatan pengabdian kepada masyarakat yang dilaksanakan di SDN Terusan 1 Indramayu berjalan dengan lancar, dengan harapan yaitu siswa meningkatkan pengetahuan serta dapat mengaplikasikan materi yang telah disampaikan, terutama tentang menjaga kebersihan diri dan lingkungan, Siswa Kelas V SDN Terusan 1 Indramayu secara sadar pentingnya menjaga kebersihan diri, hal ini dibuktikan sudah dapat membedakan jenis-jenis sampah baik organik maupun anorganik, tidak mencoret-coret dinding atau meja, menyiram WC secara bersih setelah selesai BAK/BAB. Selain itu siswa juga sadar akan pentignya kebersihan lingkungan dibuktikan dengan siswa sadar bergotong royong untuk membersihkan halaman maupun ruangan kelas.

2. Perlu adanya kerjasama berbagai pihak agar penyuluhan kesehatan dapat dilakukan tidak hanya 1 kali, namun dilakukan secara berulang-ulang atau rutin guna memantau perkembangan pengetahuan siswa mengenai kebersihan lingkungan di sekolah.

3. Diperlukan perhatian lebih pada metode yang digunakan dalam penyuluhan kesehatan. Metode yang digunakan untuk penyuluhan kesehatan sebaiknya disesuaikan dengan usia kelompok yang akan diberi penyuluhan. Misalnya untuk anak sekolah, selain penyuluhan dapat dilakukan dengan menggunakan video, penerapan atau penyampaian pendidikan kesehatan dapat menggunakan media permainan edukatif, karena dengan media permainan siswa dapat lebih mudah memahami, siswa juga tidak mengalami kebosanan dalam penyampaian materi. 


\section{DAFTAR PUSTAKA}

Arsyad, A. 2002. Media Pengajaran. Penerbit PT. Raja Grafindo Persada, Jakarta

Azizatul Yaumul Adha, Diah Rahayu Wulandari, Ari Budi Himawan. 2016.

Perbedaan Efektivitas Pemberian Penyuluhan dengan Video dan Simulasi terhadap Tingkat Pengetahuan Pencegahan TB Paru (Studi kasus di MA Husnul Khatimah Kelurahan Rowosari Kecamatan Tembalang Kota Semarang). Jurnal Kedokteran Diponegoro. Volume 5, Nomor4, Oktober2016. ISSN Online : 2540-8844

Departemen Kesehatan RI. 2009. Panduan Pengelolaan Pusat Informasi \& Konseling Kesehatan Lingkungan. Direktorat Remaja BKKBN, Jakarta.

Direktur Jenderal Pengendalian Penyakit Dan Penyehatan Lingkungan . 2015 Rencana Aksi Program Pengendalian Penyakit Dan Penyehatan Lingkungan Tahun 2015-2019

Eagle Awards Documentary Competition 2016,. INDONESIA SEHAT. Eagle Institusi Indonesia. Diakses melalui http://dinus.ac.id/repository/docs/ajar/tor.pdf

Effendy.2003. Penyuluhan Kesehatan. Jakarta.

Depkes RI. 2002. Modul Penyuluhan Kesehatan Masyarakat. Jakarta: Pusat Promosi Kesehatan

Hargono, Arief. 2013. Aplikasi Surveilans Epidemiologi Penyakit Potensial Wabah Pada Anak Sekolah Menggunakan Epi Info. FIKI 2013, 1 (1). ISSN 979-26-0263-1 Fakultas Kesehatan Masyarakat Universitas Airlangga, Surabaya.

Junus Adrianus. 2014. Pembinaan lingkungan sekolah sehat dengan pendekatan filosofi lima jari. Kendari. Diakses melalui http://simposium.gtk.kemdikbud.go.id/karya/files/tendik_2/Dra.AdrianaJu nus,M.Sos_16112016193300.pdf. Tanggal akses 20 Mei 2017

Kementerian Perencanaan Pembangunan Nasional (Bappenas) dan United Nations Children's Fund (UNICEF). 2017. Laporan Baseline SDG tentang AnakAnak di Indonesia 
Riskesdas. 2013. Badan penelitian dan pengembangan kesehatan Kementerian kesehatan RI. Jakarta

Rosso, Joy Miller, Rina Arlianti. 2009. Investasi untuk Kesehatan dan Gizi Sekolah di Indonesia, Departemen Pendidikan Nasional, Kingdom of Netherland, World Bank.

Undang-Undang Tentang Kesehatan, UU Nomor 36 Tahun 2009

Yoni Hermawan dan Komara Nur Ikhsan. 2013. Pengaruh Penyuluhan Kesehatan Lingkunga Terhadap Tingkat Pengetahuan Dan Pelaksana Kesehatan Lingkungan Smp Negeri Tambaksa Kecamatan Tambaksari Kabupaten Ciamis. Jurnal Bumi Lestari, Volume 13 No. 1, Februari 2013, hlm. 166-17 